\title{
Outcomes of surgical treatments for rectovaginal fistula and prognostic factors for successful closure: a single-center tertiary hospital experiences
}

\author{
Seung-Bum Ryoo', Heung-Kwon Oh',2, Heon-Kyun Ha ${ }^{3}$, Eon Chul Han ${ }^{1,4}$, Yoon-Hye Kwon', Inho Song', \\ Sang Hui Moon', Eun Kyung Choe ${ }^{1,5}$, Kyu Joo Park' \\ ${ }^{1}$ Division of Colorectal Surgery, Department of Surgery, Seoul National University College of Medicine, Seoul, Korea \\ ${ }^{2}$ Division of Colorectal Surgery, Department of Surgery, Seoul National University Bundang Hospital, Seongnam, Korea \\ ${ }^{3}$ Division of Colorectal Surgery, Department of Surgery, Myongji Hospital, Goyang, Korea \\ ${ }^{4}$ Division of Colorectal Surgery, Department of Surgery, Dongnam Institute of Radiological and Medical Sciences, Busan, Korea \\ ${ }^{5}$ Healthcare Research Institute, Seoul National University Hospital Healthcare System Gangnam Center, Seoul, Korea
}

Purpose: Rectovaginal fistula can result from various causes and diverse surgical procedures have developed as a result. We investigated the outcomes of surgical treatments for rectovaginal fistula according to causes and procedures.

Methods: Between 1998 and 2016, 92 patients underwent 128 operations for rectovaginal fistula. Prospectively collected data were recorded, and a retrospective review was conducted.

Results: The median age was 49 years, and low fistula occurred in 58 patients $(63.0 \%)$. The most common cause was radiation therapy, followed by pelvic operation, birth injury, perineal operation, cancer invasion, and trauma. The most common procedure during the first operation was diverting ostomy alone, followed by transanal rectal advancement flap, sphincteroplasty with perineoplasty, bowel resection, fistulectomy with seton placement, and Martius flap. Thirtyone patients $(33.7 \%)$ experienced successful closure after the first operation. Repeated operations were performed in 16 patients (17.4\%), including gracilis muscle transpositions, stem cell injections, and Martius flaps. The overall success rate was $42.4 \%(n=39)$. Radiation therapy and pelvic operation as cause of fistula were significantly poor prognostic factors $(P=$ $0.010, P=0.045)$ and Crohn disease had a tendency for poor prognostic factors ( $P=0.058)$.

Conclusion: Radiation therapy and pelvic operation for cancer were more common causes than birth injury, and these causes of rectovaginal fistula were the most important prognostic factors. An individualized approach and repeated surgeries with complex or newly developed procedures, even among high-risk causes of fistula, may be necessary to achieve successful closure.

[Ann Surg Treat Res 2019;97(3):149-156]

Key Words: Fistula, Rectum, Surgery, Vagina

\section{INTRODUCTION}

Rectovaginal fistula (RVF) accounts for less than 5\% of all perianal fistulas, but leads to not only physical problems, including inflammation and irritation, but also emotional distress and social and sexual dysfunction. Previous reports found birth injury to be the most common cause of RVF accounting for $60 \%-80 \%$. It may result from a third- or fourth-
Received May 16, 2019, Revised July 4, 2019,

Accepted July 19,2019

Corresponding Author: Kyu Joo Park

Department of Surgery, Seoul National University Hospital, Seoul National University College of Medicine, 101 Daehak-ro, Jongno-gu, Seoul 03080, Korea

Tel: +82-2-2072-2901, Fax: +82-2-766-3975

E-mail: kjparkmd@plaza.snu.ac.kr

ORCID: https://orcid.org/0000-0002-9134-7426
- The results of this study were presented at the 7th annual meeting of the European Society of Coloproctology, which was held in September 2012 in Vienna, Austria.

Copyright (c) 2019, the Korean Surgical Society

(c) Annals of Surgical Treatment and Research is an Open Access Journal. All articles are distributed under the terms of the Creative Commons Attribution NonCommercial License (http://creativecommons.org/licenses/by-nc/4.0/) which permits unrestricted non-commercial use, distribution, and reproduction in any medium, provided the original work is properly cited. 
degree perineal laceration during vaginal delivery, and anal incontinence can develop, as with sphincter injury. Perianal infection or prior perianal surgery can be a cause of RVF. Inflammatory bowel diseases are also causes of RVF and should be suspected when a fistula is complex or recurrent. Pelvic irradiation is not an uncommon cause in cancer patients. Because cancer invasion can also develop a fistula, evaluating tumor recurrence at the fistula site is important in these patients [1-4].

Numerous surgical procedures have been developed to resolve RVFs; the approach chosen in each case depends on fistula size, the presence of a sphincter defect, the existence of combined fistulas, and the causes of the disease. However, the location of the fistula opening is the most important feature to consider when selecting an appropriate procedure. In a simple low fistula, transvaginal or transanal local repair can be performed and are safe and feasible methods, though the transanal rectal advancement flap is more familiar to colorectal surgeons. More complex procedures, including gracilis muscle transposition and rectal sleeve advancement flap repair, may be necessary to repair complex fistulas. Often, high fistula should be treated with abdominal operations, such as proctectomy or diversion colostomy $[5,6]$.

The purpose of this study was to investigate the outcome of surgical treatments for RVF according to the various causes and procedures and to analyze the prognostic factors for successful RVF closure.

\section{METHODS}

Between 1998 and 2016, 92 patients underwent 128 operations for RVF at our institute. We prospectively registered these patients and retrospectively reviewed the medical records. This study was approved by the Institutional Review Board of Seoul National University Hospital (approval number: H-1205107-410).

Diagnosis was based on patient history, digital rectal examination, and vaginal examination, as well as radiological findings, such as CT or fistulogram. Low fistula was defined as a fistula located from near the dentate line to the posterior vaginal fourchette and around the anal sphincter complex and was easy to detect. High fistula was defined as a fistula located from near the peritoneal reflection to the cervix and was detected, with difficulty, by digital examination through the anus or vagina. A sphincter defect was evaluated preoperatively by digital rectal examination or transrectal ultrasonography. Operative methods were selected according to disease cause, location of the fistula opening, and patient clinical condition. Successful closure was confirmed based on patient symptoms, digital rectal examination, or fistulogram during follow-up. The risk factors for failure of closure, which are fistula continuance or recurrence, were also analyzed.

Statistical analysis was conducted using IBM SPSS Statistics ver. 21.0 (IBM Co., Armonk, NY, USA). Student t-test was used to compare the averages of variables. Univariate analysis was performed using Pearson chi-square test and Fisher exact test. Multivariate analysis was performed by logistic regression. In statistical analyses, $\mathrm{P}<0.05$ was regarded as indicative of significance.

\section{RESULTS}

\section{Clinical characteristics and causes of RVF}

The median age of the 92 patients was 49 years (range, 16-80 years). The most common symptom was stool leakage through the vagina, which occurred in 83 patients $(90.2 \%)$. Other symptoms were vaginal discomfort, menstruation through the anus, fecal incontinence, and pus drainage through the vagina. Initially, 11 patients (12.0\%) presented with recurrent fistula at our institute, and the median number of previous operations was 2 (range, 1-5). Fistula in the neorectum of the ileal pouch was found in 8 patients (8.7\%), and multiple fistulas, including $\mathrm{RVF}$ and rectovesical fistula, were found in 2 patients $(2.2 \%)$. Low fistula occurred in 58 patients (63.0\%), and high fistula occurred in 34 patients (37.0\%).

The most common cause of fistula was radiation therapy (RT) for cancer ( $n=27$ [29.3\%]). The median period from RT to fistula development was 11 months (range, 0-336 months). RT was performed for cervical cancer in 20 patients $(74.1 \%)$, rectal cancer in 6 patients (22.2\%), and bladder cancer in one patient (3.7\%). Fistula occurred as a complication after pelvic operations with rectal resection and anastomosis for rectal cancer or due to rectal invasion of gynecologic cancer in 26 patients (28.3\%). Trans-abdominal hysterectomy was simultaneously performed in 4 patients (15.4\%). Pouch vaginal fistula after total proctocolectomy with ileal pouch-anal anastomosis (IPAA) occurred in 8 patients (30.8\%). Seven of these patients underwent IPAA for ulcerative colitis (UC), and one patient underwent IPAA for familial adenomatous polyposis. The complications that occurred after perineal operations were related to injection therapy for hemorrhoids, vaginal cyst removal, incision and drainage for perianal abscess, transvaginal hysterectomy with posterior repair, McIndoe operation for vaginal reconstruction, and operation for urinary incontinence. The clinical characteristics and causes of fistula are presented in Table 1. According to the location of fistula opening, low fistulas were significantly related to pelvic operation, birth injury, and perineal operations $(\mathrm{P}=0.007, \mathrm{P}=$ $0.001, P=0.012$ ), and high fistulas were significantly related to $\mathrm{RT}$ and cancer invasion $(\mathrm{P}<0.001, \mathrm{P}=0.002)$ (Table 2). 


\section{Operations for RVF}

The most common surgical procedure conducted during the first operation at our institute was diverting ostomy alone, which was performed in 53 patients (57.6\%). Thirty-two patients presented with high fistula resulting from RT or cancer invasion, and 21 patients presented with low fistula, usually resulting from rectal resection. Transanal rectal advancement

Table 1. Clinical characteristics of the patients with rectovaginal fistula $(n=92)$

\begin{tabular}{|c|c|}
\hline Characteristic & No. $(\%)$ \\
\hline \multicolumn{2}{|l|}{ Age (yr) } \\
\hline$\geq 40$ & $59(61.1)$ \\
\hline$<40$ & $33(35.9)$ \\
\hline \multicolumn{2}{|c|}{ Body mass index $\left(\mathrm{kg} / \mathrm{m}^{2}\right)$} \\
\hline$\leq 18.5$ & $13(14.1)$ \\
\hline $18.6-23$ & $43(46.7)$ \\
\hline$>23$ & $36(39.1)$ \\
\hline \multicolumn{2}{|l|}{ Initial presentation } \\
\hline First Onset & $81(88.0)$ \\
\hline Recurrent & $11(12.0)$ \\
\hline \multicolumn{2}{|l|}{ Type of fistula } \\
\hline Rectovaginal & $82(89.1)$ \\
\hline Pouch vaginal & $8(8.7)$ \\
\hline Multiple & $2(2.2)$ \\
\hline \multicolumn{2}{|l|}{ Location of fistula } \\
\hline Low & $58(63.0)$ \\
\hline High & $34(37.0)$ \\
\hline \multicolumn{2}{|l|}{ Sphincter defect } \\
\hline Yes & $5(5.4)$ \\
\hline No & $87(94.6)$ \\
\hline \multicolumn{2}{|l|}{ Causes of fistula } \\
\hline Radiation therapy & $27(29.3)$ \\
\hline Pelvic operation & $26(28.3)$ \\
\hline Birth injury & $15(16.3)$ \\
\hline Perineal operation & $11(12.0)$ \\
\hline Cancer invasion & $7(7.6)$ \\
\hline Crohn disease & $4(4.3)$ \\
\hline Trauma & $1(1.1)$ \\
\hline Unknown & $1(1.1)$ \\
\hline
\end{tabular}

Table 2. The relationship between fistula cause and location $(\mathrm{n}=92)$

\begin{tabular}{lccr}
\hline \multicolumn{1}{c}{ Causes } & Low & High & P-value \\
\hline Radiation therapy & $5(18.5)$ & $22(81.5)$ & $<0.001^{*}$ \\
Pelvic operation & $22(84.6)$ & $4(15.4)$ & $0.007^{*}$ \\
Birth injury & $15(100)$ & $0(0)$ & $0.001^{*}$ \\
Perineal operation & $11(100)$ & $0(0)$ & $0.012^{*}$ \\
Cancer invasion & $0(0)$ & $7(100)$ & $0.002^{*}$ \\
Crohn disease & $3(75.0)$ & $1(25.0)$ & $>0.999$ \\
Trauma & $1(100)$ & $0(0)$ & $>0.999$ \\
Unknown & $1(100)$ & $0(0)$ & $>0.999$ \\
\hline
\end{tabular}

Values are presented as number (\%).

$* \mathrm{P}<0.05$, statistically significant difference.

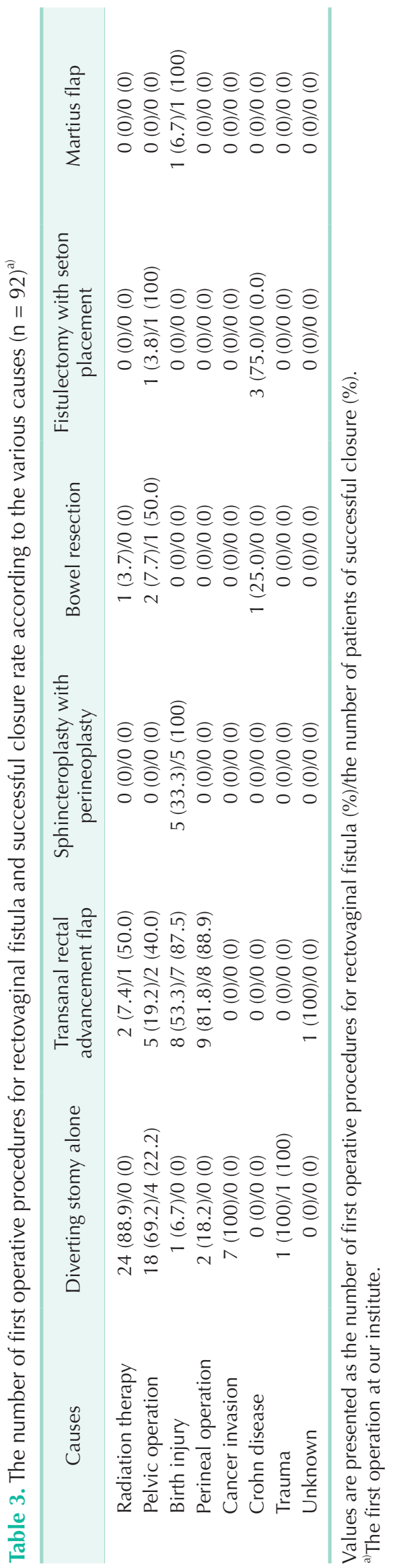

Annals of Surgical Treatment and Research 
flap, which was the second most common procedure, was performed in 25 patients (27.2\%). All cases of low fistula resulted from birth injury, perineal operation, pelvic operation, or RT. Sphincteroplasty with perineoplasty was performed in 5 patients (5.4\%) who suffered from a sphincter defect due to a birth injury. Fistulectomy with seton placement was used in 4 patients (4.3\%); of these patients, 3 exhibited low fistula due to Crohn disease, and 1 exhibited low fistula due to IPAA for UC. Bowel resection was performed in 4 patients (4.3\%) who presented with low fistula resulting from rectal resection or IPAA for UC or high fistula resulting from RT or Crohn disease. Three patients (7.7\%) underwent a protective ostomy in combination with other surgical procedures. The number of patients and successful closure rate after the first operation at our institute according to the causes of RVF are described in Table 3.

The median follow-up period was 17 months (range, 0-123 months), and 31 patients (33.7\%) experienced successful closure of the fistula after the first operation. Forty-five (48.9\%) patients had not undergone take-down of a diverting ostomy.
Repeated operations were performed in 16 patients (17.4\%) who had persistent or recurrent fistula, which resulted from pelvic operation in 9 patients, Crohn disease in 3 patients, RT in 2 patients, birth injury in 1 patient, and perineal operation in 1 patient. Thirty-six additional operations were performed, including 12 transanal rectal advancement flaps. The median number of operations was 3 (range, 2-6), including the first operation. Successful closure was achieved in 8 patients (50.0\%); thus, overall successful closure was achieved in 39 patients (42.4\%). Protective ostomy was achieved in 21 operations (75.0\%) in 12 patients $(75.0 \%)$, and take-down of ostomy was achieved in 6 patients (37.5\%). Recurrent operations and success rates are described in Fig. 1 and the success rates of surgical procedures for RVF with total number of operations is in Table 4.

\section{Prognostic factors for the successful closure of RVF}

In univariate analysis, RT was a significantly poor prognostic factor, but low fistula, sphincter defect, birth injury as cause of the fistula were good prognostic factors for successful closure (Table 5). Using multivariate analysis, the fistula causes of RT

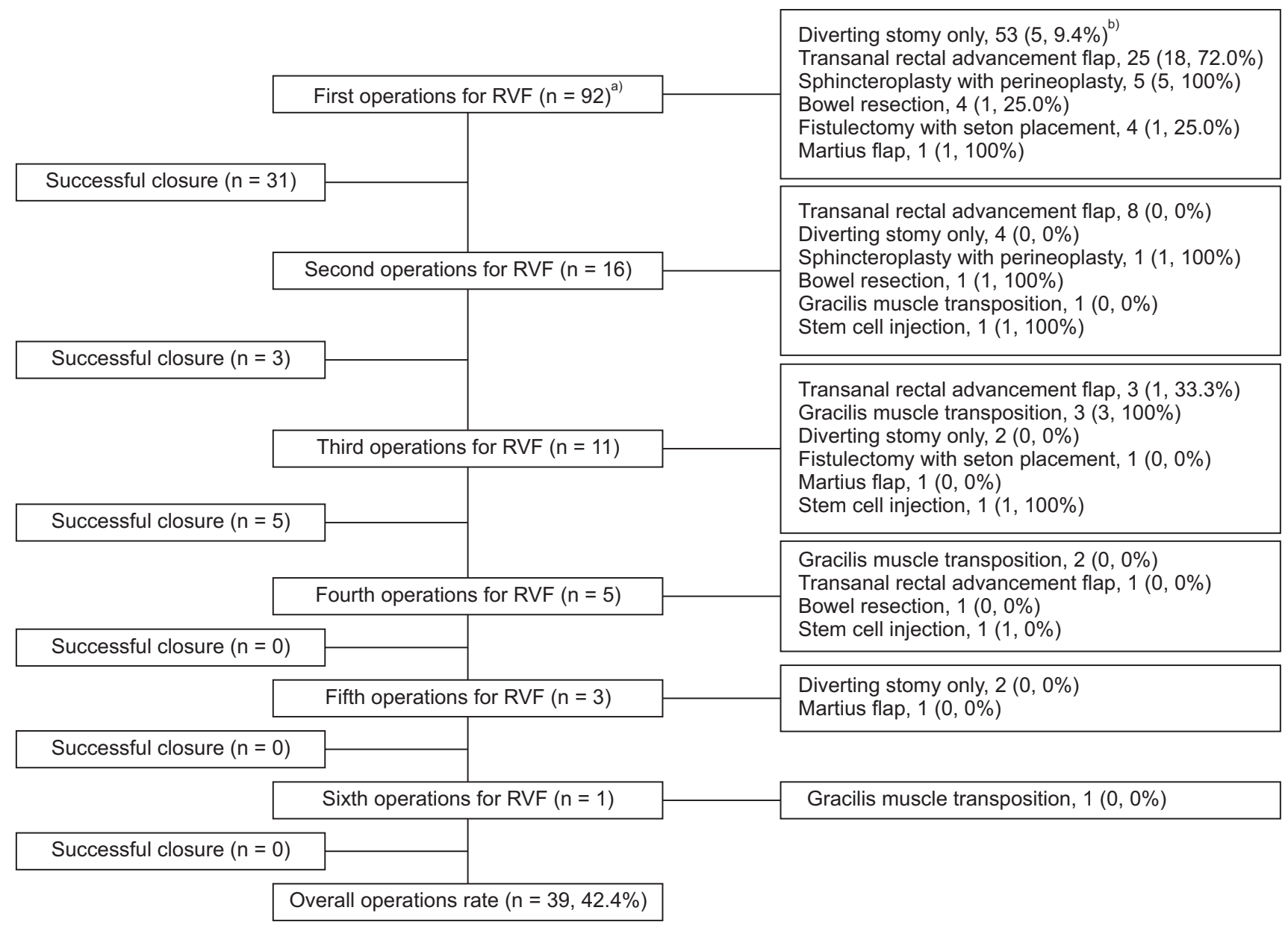

Fig. 1. Recurrent operations for rectovaginal fistula $(n=128)$. RVF, rectovaginal fistula. ${ }^{a}$ The first operation in our institute. ${ }^{b}$ The number of patients and rate of successful closure after surgical procedure. 
Table 4. The success rate of surgical procedures for rectovaginal fistula with total operations $(n=128)$

\begin{tabular}{lc}
\hline \multicolumn{1}{c}{ Surgical procedures } & $\begin{array}{c}\text { Successful } \\
\text { closure, } \mathrm{n}(\%)\end{array}$ \\
\hline Surgical procedure & \\
Diverting stomy alone & $5(8.2)$ \\
Transanal rectal advancement flap & $19(51.4)$ \\
Gracilis muscle transposition & $3(42.9)$ \\
Bowel resection & $2(33.3)$ \\
Sphincteroplasty with perineoplasty & $6(100)$ \\
Fistulectomy with seton & $1(20.0)$ \\
Stem cell injection & $2(66.7)$ \\
Martius flap & $1(33.3)$ \\
Protective stomy & \\
Yes & $11(25.6)$ \\
No & $27(52.9)$ \\
\hline
\end{tabular}

Table 5. Prognostic factors for successful closure of rectovaginal fistula with total operations $(n=128)$

\begin{tabular}{|c|c|c|}
\hline Variable & $\begin{array}{c}\text { Successful } \\
\text { closure, n (\%) }\end{array}$ & P-value (uni) \\
\hline Age (yr) & & 0.217 \\
\hline$\geq 40$ & $20(26.3)$ & \\
\hline$<40$ & $19(36.5)$ & \\
\hline Body mass index $\left(\mathrm{kg} / \mathrm{m}^{2}\right)$ & & 0.104 \\
\hline$\leq 18.5$ & $3(14.3)$ & \\
\hline $18.6-23$ & $15(28.3)$ & \\
\hline$>23$ & $21(38.9)$ & \\
\hline Initial presentation & & 0.787 \\
\hline First onset & $24(29.6)$ & \\
\hline Recurrent & $15(31.9)$ & \\
\hline Type of fistula & & 0.141 \\
\hline Rectovaginal & $37(33.6)$ & \\
\hline Pouch vaginal & $2(13.3)$ & \\
\hline Multiple & $0(0)$ & \\
\hline Location of fistula & & $<0.001^{*}$ \\
\hline Low & $38(40.4)$ & \\
\hline High & $1(2.9)$ & \\
\hline Sphincter defect & & $0.001^{*}$ \\
\hline Yes & $6(100)$ & \\
\hline No & $33(27.0)$ & \\
\hline \multicolumn{3}{|l|}{ Causes of fistula } \\
\hline Radiation therapy & $2(6.5)$ & $0.001^{*}$ \\
\hline Pelvic operation & $11(23.4)$ & 0.186 \\
\hline Birth injury & $14(87.5)$ & $<0.001^{*}$ \\
\hline Perineal operation & $9(69.2)$ & $0.003^{*}$ \\
\hline Cancer invasion & $0(0)$ & 0.100 \\
\hline Crohn disease & $2(16.7)$ & 0.343 \\
\hline Trauma & $1(100)$ & 0.305 \\
\hline Unknown & $0(0)$ & $>0.999$ \\
\hline
\end{tabular}

$* P<0.05$, statistically significant difference; uni, univariate analysis.
Table 6. Multivariable analysis for prognostic factors for successful closure of rectovaginal fistula with total operations $(\mathrm{n}=128)$

\begin{tabular}{lcl}
\hline \multicolumn{1}{c}{ Causes of fistula } & HR $(95 \% \mathrm{Cl})$ & $\begin{array}{c}\text { P-value } \\
\text { (multi) }\end{array}$ \\
\hline Radiation therapy & $16.475(1.957-138.685)$ & $0.010^{*}$ \\
Pelvic operation & $4.572(1.032-20.249)$ & $0.045^{*}$ \\
Crohn disease & $8.794(0.930-83.165)$ & 0.058 \\
\hline
\end{tabular}

$\mathrm{HR}$, hazard ratio; $\mathrm{Cl}$, confidence interval.

${ }^{*} \mathrm{P}<0.05$, statistically significant difference; multi, multivariate analysis.

and pelvic operation were poor prognostic factors for successful closure $(P=0.010, P=0.045)$. Crohn disease had a tendency of poor prognosis $(\mathrm{P}=0.058)$ (Table 6 ).

\section{DISCUSSION}

RVFs have various causes, the most common of which were found to be RT and pelvic operation in our study. Fistula location differed according to the causes, and low fistula was more common. A variety of operations was performed in patients with persistent or recurrent RVF, and complex procedures were more frequent with repeated operations. The overall successful closure rate was $42.4 \%$, and better outcomes were achieved for RVF from birth injury or perineal operation. However, RVF from RT, pelvic operation, or Crohn disease presented poor prognosis. Although diverting ostomy alone could close some of the RVFs from trauma or pelvic operation, it was not found to be effective for RVF from RT or cancer invasion.

In this study, RT for cancer was the most common cause of RVF. We assumed that because our hospital is a tertiary hospital, there may have been more patients with causes of RT or pelvic operation from cancer than at other centers. Radiation damage is thought to be related to radiation dose and the fistulas induced by RT are difficult to heal via local repair because irradiated tissue exhibits friability or ischemic fibrosis. Combined fistulas, such as enterovaginal, vesicovaginal, and rectovesical fistulas, are also common among recipients of RT. For the 2 patients in our study who had multiple fistulas, the cause was RT. Resection of the affected bowel or diverting colostomy is frequently required in these patients. Unfortunately, colostomy may be permanent because spontaneous fistula closure is rare $[7,8]$. Most of the patients who received RT had high fistulas and underwent diverting ostomy alone in this study. For the patient who was treated with diverting ostomy alone, it was not possible to take down the ostomy during the follow-up period. Successful closure was achieved in only 2 patients (6.5\%) with low fistulas after transanal rectal advancement flap and gracilis muscle 
transposition.

Pelvic operation with rectal resection can lead to iatrogenic injury of the rectovaginal septum due to the double-stapling technique, or develop postoperative leakage at the anastomosis site. RVF from pelvic operation with rectal resection is also difficult to close, and complex procedures may be needed $[9,10]$. Among our patients, successful closure was achieved in only $23.4 \%$ of cases, despite repeated operations from the diverting ostomy alone to gracilis muscle transposition.

Birth injury is known to be a common cause of RVF, but the number of RVFs resulting from this cause has been declining due to a decrease in the number of severe obstetric perineal lacerations resulting from the minimal use of episiotomy and operative vaginal delivery [11]. Most fistulas resulting from birth injury can be successfully treated by transanal local repair with rectal advancement flap, and sphincteroplasty or perineoplasty may be necessary in some cases involving sphincter injury [12]. In this study, birth injury was the third most common cause, and transanal rectal advancement flap or sphincteroplasty with perineoplasty was performed in most patients. The success rate was $87.5 \%$, representing the best results achieved for all fistula causes. Transvaginal approaches may be better in terms of exposure and are easier to perform by obstetric and gynecologic surgeons, and success rates are reportedly as high as those achieved using the transanal approach $[13,14]$. Although insufficient studies comparing these 2 approaches have been conducted, it is assumed that because the fistula opening in the anus represents the site experiencing the greatest pressure, closure at the anal site is important for achieving successful outcomes $[15,16]$.

Inflammatory bowel diseases are common causes of RVF. Although transanal local repair may be acceptable in patients with Crohn disease without rectal inflammation, the recurrence rate is reportedly as high as $25 \%-50 \%$, and further complex procedures are likely necessary [17,18]. Although combined medical treatments using anti-TNF- $\alpha$ and infliximab are promising, these treatments have not yet been found to be satisfactory in terms of long-term outcome [19,20]. Recently, adipose-derived stem cells, representing a novel treatment, have been used for recurrent Crohn anal fistula and are reportedly safe and feasible [21-23]. We performed stem cell injections in 3 patients, and complete closure was achieved in 2 of them $(66.7 \%)$. Although the long-term effects of stem cells have not yet been determined, this treatment may also represent an effective option for RVF treatment. Fistula after IPAA for UC is also difficult to manage due to the high recurrence rate after local repair [24]. Only 2 patients (28.6\%) with pouch vaginal fistulas achieved successful closure despite repeated operation, including pouch excision and reformation of the IPAA in 1 patient.

Although numerous surgical procedures have been deve- loped to treat RVF, no gold standard procedure currently exists. The choice of procedure should depend on the clinical features of the patients, including fistula cause. The use of an individualized approach involving a precise surgical technique can yield successful closure of RVF [1,15]. The success rates obtained in previous studies have been diverse, ranging from $30 \%$ to approximately $90 \%$, because the patients presented with various causes of RVF and a variety of surgical procedures were used [25-27]. The operative treatment for recurrent RVF can be more complex, and the results of local repair with rectal flap have been disappointing [28]. The use of a muscle transplant, such as gracilis muscle transposition, has been attempted for fistula repair, and an additional variety of procedures, such as rectal sleeve advancement flap, Martius flap, proctectomy, and diversion colostomy, may be necessary $[25,29,30]$. Recently, the aggressive use of diverting ostomy and major procedures has been suggested [26]; however, in this study, we tended to select gracilis muscle transposition or Martius flap for repeated operations, with success rates of $42.9 \%$ and $33.3 \%$, respectively. Although these success rates were not as high as that obtained with transanal rectal advancement flap, we considered that the success rate may not depend on the procedures used but on the cause of RVF, which were mainly RT, pelvic operation, and Crohn disease in the present study. Achieving closure of recurrent RVF is important, and surgeons should aim to improve the outcomes of operative treatments for RVF even in patients who undergo repeated complex procedures.

This study has the limitations associated with a retrospective review, and the clinical features of RVF resulting from individual causes were not fully represented due to the small number of patients involved. As the number of patients with each cause of RVF was also small, we could not analyze the separate results from the homogenous populations with the same causes of fistula. Further research with a large number of patients is necessary. Also, the follow-up periods were considered insufficiently long to evaluate the outcomes; however, the patients who were treated successfully for simple low fistula in our study did not need to return to the hospital for a long time, and the patients who had fistula associated with RT or cancer invasion may have died early due to their underlying disease. Despite the lack of high-quality prospective studies evaluating the outcomes of surgical treatment for RVF, we verified that the RVF cause may be the most important prognostic factor and that diverting ostomy alone was sufficient to close an RVF resulting from RT or pelvic operation.

In conclusion, RVF results from various causes and can be treated successfully by a variety of surgical procedures. The treatment outcome differed according to clinical presentation, fistula cause, and operative procedure, and the cause of RVF was the most important prognostic factor for successful closure. RT, pelvic operation or Crohn disease is increasing at tertiary 
hospitals and the surgical procedure involving diverting ostomy alone is not enough in these high-risk fistulas. Taking an individualized approach is necessary for achieving successful outcomes, and surgeons should attempt to close fistulas with repeated procedures, including complex or novel procedures, even for persistent or recurrent fistulas with a high risk of causes of RVF.

\section{CONFLICTS OF INTEREST}

No potential conflict of interest relevant to this article was reported.

\section{ACKNOWLEDGEMENTS}

We thank the members of the Medical Research Collaborating Center at Seoul National University Hospital for their assistance with the statistical analysis.

\section{REFERENCES}

1. Saclarides TJ. Rectovaginal fistula. Surg Clin North Am 2002;82:1261-72.

2. Ozuner G, Hull TL, Cartmill J, Fazio VW. Long-term analysis of the use of transanal rectal advancement flaps for complicated anorectal/vaginal fistulas. Dis Colon Rectum 1996;39:10-4.

3. Hannaway CD, Hull TL. Current considerations in the management of rectovaginal fistula from Crohn's disease. Colorectal Dis 2008;10:747-55.

4. Lucarotti ME, Mountford RA, Bartolo DC. Surgical management of intestinal radiation injury. Dis Colon Rectum 1991; 34:865-9.

5. Rothenberger DA, Christenson CE, Balcos EG, Schottler JL, Nemer FD, Nivatvongs $S$, et al. Endorectal advancement flap for treatment of simple rectovaginal fistula. Dis Colon Rectum 1982:25:297-300.

6. Pinto RA, Peterson TV, Shawki S, Davila GW, Wexner SD. Are there predictors of outcome following rectovaginal fistula repair? Dis Colon Rectum 2010;53:1240-7.

7. Pricolo VE, Shellito PC. Surgery for radiation injury to the large intestine. Variables influencing outcome. Dis Colon Rectum 1994:37:675-84.

8. Piekarski JH, Jereczek-Fossa BA, Nejc D, Pluta P, Szymczak W, Sek P, et al. Does fecal diversion offer any chance for spontaneous closure of the radiation-induced rectovaginal fistula? Int J Gynecol Cancer 2008;18:66-70.

9. Kosugi C, Saito N, Kimata Y, Ono M,
Sugito M, Ito M, et al. Rectovaginal fistulas after rectal cancer surgery: incidence and operative repair by gluteal-fold flap repair. Surgery 2005;137:329-36.

10. Matthiessen P, Hansson L, Sjodahl R, Rutegard J. Anastomotic-vaginal fistula (AVF) after anterior resection of the rectum for cancer--occurrence and risk factors. Colorectal Dis 2010;12:351-7.

11. Brown HW, Wang L, Bunker $\mathrm{CH}$, Lowder JL. Lower reproductive tract fistula repairs in inpatient US women, 1979-2006. Int Urogynecol J 2012;23:403-10.

12. Athanasiadis S, Oladeinde I, Kuprian A, Keller B. Endorectal advancement flapplasty vs. transperineal closure in surgical treatment of rectovaginal fistulas. A prospective long-term study of 88 patients. Chirurg 1995:66:493-502.

13. Rahman MS, Al-Suleiman SA, El-Yahia AR, Rahman J. Surgical treatment of rectovaginal fistula of obstetric origin: a review of 15 years' experience in a teaching hospital. J Obstet Gynaecol 2003; 23:607-10.

14. Maeda K, Koide Y, Hanai T, Sato H, Masumori K, Matsuoka H, et al. The longterm outcome of transvaginal anterior levatorplasty for intractable rectovaginal fistula. Colorectal Dis 2015;17:1002-6.

15. Debeche-Adams TH, Bohl JL. Rectovaginal fistulas. Clin Colon Rectal Surg 2010;23: 99-103.

16. Ruffolo C, Scarpa M, Bassi N, Angriman I. A systematic review on advancement flaps for rectovaginal fistula in Crohn's disease: transrectal vs transvaginal approach. Colorectal Dis 2010;12:1183-91.

17. Sonoda T, Hull T, Piedmonte MR, Fazio VW. Outcomes of primary repair of anorectal and rectovaginal fistulas using the endorectal advancement flap. Dis Colon Rectum 2002;45:1622-8.

18. Loffler T, Welsch T, Muhl S, Hinz U, Schmidt J, Kienle P. Long-term success rate after surgical treatment of anorectal and rectovaginal fistulas in Crohn's disease. Int J Colorectal Dis 2009;24:521-6.

19. Sands BE, Anderson FH, Bernstein CN, Chey WY, Feagan BG, Fedorak RN, et al. Infliximab maintenance therapy for fistulizing Crohn's disease. N Engl J Med 2004:350:876-85.

20. Ruffolo C, Penninckx F, Van Assche G, Vermeire S, Rutgeerts P, Coremans G, et al. Outcome of surgery for rectovaginal fistula due to Crohn's disease. Br J Surg 2009:96:1190-5.

21. Cho YB, Lee WY, Park KJ, Kim M, Yoo HW, Yu CS. Autologous adipose tissue-derived stem cells for the treatment of Crohn's fistula: a phase I clinical study. Cell Transplant 2013:22:279-85.

22. Cho YB, Park KJ, Yoon SN, Song KH, Kim DS, Jung SH, et al. Long-term results of adipose-derived stem cell therapy for the treatment of Crohn's fistula. Stem Cells Transl Med 2015:4:532-7.

23. Park KJ, Ryoo SB, Kim JS, Kim TI, Baik SH, Kim HJ, et al. Allogeneic adipose-derived 
stem cells for the treatment of perianal fistula in Crohn's disease: a pilot clinical trial. Colorectal Dis 2016;18:468-76.

24. Tsujinaka S, Ruiz D, Wexner SD, Baig MK, Sands DR, Weiss EG, et al. Surgical management of pouch-vaginal fistula after restorative proctocolectomy. J Am Coll Surg 2006:202:912-8.

25. Furst A, Schmidbauer C, Swol-Ben J, Iesalnieks I, Schwandner O, Agha A. Gracilis transposition for repair of recurrent anovaginal and rectovaginal fistulas in Crohn's disease. Int J Colorectal Dis 2008:23:349-53.

26. Corte H, Maggiori L, Treton X, Lefevre JH, Ferron M, Panis Y. Rectovaginal fistula: what is the optimal strategy?: an analysis of 79 patients undergoing 286 procedures. Ann Surg 2015;262:855-60.

27. Sjoveian S, Vangen S, Mukwege D, Onsrud M. Surgical outcome of obstetric fistula: a retrospective analysis of 595 patients. Acta Obstet Gynecol Scand 2011;90:75360.
28. MacRae HM, McLeod RS, Cohen Z, Stern H, Reznick R. Treatment of rectovaginal fistulas that has failed previous repair attempts. Dis Colon Rectum 1995:38:921-5.

29. Andreani SM, Dang HH, Grondona P, Khan AZ, Edwards DP. Rectovaginal fistula in Crohn's disease. Dis Colon Rectum 2007:50:2215-22.

30. Kniery KR, Johnson EK, Steele SR. Martius flap for repair of recurrent rectovaginal fistulas. Dis Colon Rectum 2015:58:1210. 